\title{
The Venous Pump in the Legs as a Determinant of Pulmonary Capillary Filling *
}

\author{
Walter J. Daly, Richard A. Krumholz, $†$ and Joseph C. Ross \\ (From the Department of Medicine and the Heart Research Center, Indiana University School \\ of Medicine, Indianapolis, Ind.)
}

The regulation of the pulmonary capillary bed in normal and abnormal situations has been studied extensively in recent years by a variety of techniques. Those based on the carbon monoxide diffusing capacity have been particularly intriguing. Because exercise can produce greater increases in breath-holding diffusing capacity $\left(\mathrm{DL}_{\mathrm{Co}}\right)$ than can be obtained by other means (1), the mechanism whereby this effect of exercise is accomplished has considerable importance, since it implies an enlargement of the effective pulmonary capillary bed (2-4).

Previous studies have shown that increases in pulmonary blood flow alone do not increase $\mathrm{DL}_{\mathrm{Co}}$ $(1,5,6)$. Theoretic considerations predict that $\mathrm{DL}_{\mathrm{co}}$ should be relatively independent of pulmonary capillary blood flow but quite sensitive to the instantaneous volume of blood exposed to the alveolar gas (7). Increases in $\mathrm{DL}_{\mathrm{Co}}$ during exercise are furthermore probably not dependent upon changes in ventilation $(1,8)$ or blood $\mathrm{pH}$ (1). Procedures designed to transfer blood from the peripheral circulation to the lung and to increase pulmonary vascular pressures do increase $\mathrm{DL}_{\mathrm{CO}}$ somewhat $(5,9)$, primarily by increasing pulmonary capillary blood volume.

The present study was designed to examine the role of venous pumping action of the legs in making more blood available to the pulmonary capillary bed and consequently contributing to the increase in $\mathrm{DL}_{\mathrm{CO}}$ observed during exercise and to the maintenance of pulmonary capillary volume in upright postures.

\footnotetext{
* Submitted for publication July 20, 1964 ; accepted October 29, 1964.

This study was supported in part by research grants H6228 and H4080 from the National Heart Institute and in part by U. S. Air Force contract 33(616) 8378 .

$\dagger$ This work was done during tenure of a U. S. Public Health Service postdoctoral research fellowship.
}

\section{Methods}

Twenty-five trained normal men, ages 21 through 37, were used in this study. They came to the laboratory from their regular work. They were not fasting when studied, nor was there any attempt to ensure more than 15 minutes rest before beginning measurements.

"Passive" leg motion was performed with subjects supine and sitting. Their feet were fastened to bicycle pedals and rotated at a frequency of 40 to $50 \mathrm{rpm}$ with a stroke radius of $17 \mathrm{~cm}$. The subjects were trained to relax as much as possible. Each period of passive motion continued at least 3 minutes. Ventilation and mixed expired oxygen concentration were monitored continuously during rest and passive leg motion. The subjects breathed air from a recording Tissot spirometer using a HansRudolph valve. A portion of the mixed expirate was pumped continuously from a mixing chamber through a paramagnetic oxygen analyzer. The $90 \%$ response time of this sampling system was 30 seconds. Minute ventilation was corrected to BTPS (body temperature, pressure, saturated with water). Oxygen consumption was calculated from the ventilation and corresponding expired oxygen concentrations after lag time correction. No correction was made for the difference in inspired and expired minute volumes. The magnitude of the error introduced thereby depends upon the rate of oxygen consumption and the deviation of the respiratory exchange ratio (RQ) from 1.0. In the range of $\mathrm{O}_{2}$ consumption observed in this study and assuming a range of $R Q$ from 0.8 to 1.0 , this error does not exceed $1 \%$. In all cases, $\mathrm{O}_{2}$ consumption was calculated after a steady state of ventilation and mixed expired $\mathrm{O}_{2}$ concentration had been achieved.

$\mathrm{DL}_{\text {co }}$ was measured in duplicate when subjects were at rest and after 2 to 3 minutes of passive leg motion in sitting or supine positions and sitting with thigh tourniquets inflated to $250 \mathrm{~mm} \mathrm{Hg}$. All comparisons between rest and motion refer to measurements made in the same position. In some cases $\mathrm{DL}_{\text {Lo }}$ was also measured during the first 10 seconds of leg motion with the breath-holding period beginning at the onset of the first stroke of leg motion.

DLco was measured by the Krogh breath-holding technique as modified by Ogilvie, Forster, Blakemore, and Morton (10) and as previously reported in detail from this laboratory for use with a gas chromatograph (11). The gas mixture used contained $0.5 \% \mathrm{CO}, 1.0 \%$ neon, 
TABLE I

Pulmonary diffusing capacity (DLco) and oxygen consumption during passive leg motion in seated normal subjects

\begin{tabular}{|c|c|c|c|c|}
\hline \multirow[b]{2}{*}{ Subject } & \multicolumn{2}{|c|}{ Dlco } & \multicolumn{2}{|c|}{$\mathrm{O}_{2}$ consumption } \\
\hline & Rest & $\begin{array}{c}\text { Passive } \\
\text { motion }\end{array}$ & Rest & $\begin{array}{l}\text { Passive } \\
\text { motion }\end{array}$ \\
\hline & \multicolumn{2}{|c|}{$m l / \min \times m m H g$} & \multicolumn{2}{|c|}{$m l / m i n$} \\
\hline $\begin{array}{l}\text { R.K. } \\
\text { B.D. } \\
\text { D.D. } \\
\text { R.T. } \\
\text { N.L. } \\
\text { J.S. } \\
\text { R.S. } \\
\text { W.D. } \\
\text { P.Mc. } \\
\text { C.A. } \\
\text { D.K. } \\
\text { M.L. } \\
\text { S.G. } \\
\text { R.D. } \\
\text { T.S. } \\
\text { J.C. } \\
\text { B.M. } \\
\text { J.R. } \\
\text { B.H. } \\
\text { B.L. } \\
\text { J.M. } \\
\text { J.O. }\end{array}$ & $\begin{array}{l}24.6 \\
35.9 \\
40.1 \\
36.5 \\
25.6 \\
26.1 \\
41.1 \\
34.8 \\
36.2 \\
23.5 \\
38.5 \\
33.3 \\
28.1 \\
42.4 \\
31.6 \\
33.0 \\
20.9 \\
30.3 \\
39.9 \\
43.4 \\
31.7 \\
30.8\end{array}$ & $\begin{array}{l}26.0 \\
38.4 \\
42.2 \\
36.8 \\
28.2 \\
31.4 \\
43.8 \\
39.4 \\
40.0 \\
28.3 \\
43.8 \\
36.5 \\
34.3 \\
47.5 \\
37.3 \\
39.9 \\
22.4 \\
34.2 \\
48.0 \\
47.8 \\
31.2 \\
35.2\end{array}$ & $\begin{array}{l}342 \\
431 \\
430 \\
291 \\
342 \\
314 \\
336 \\
333 \\
405 \\
282 \\
353 \\
367 \\
321 \\
357 \\
294 \\
295 \\
293 \\
256 \\
328 \\
350 \\
262 \\
292\end{array}$ & $\begin{array}{l}345 \\
413 \\
401 \\
358 \\
344 \\
356 \\
361 \\
383 \\
416 \\
273 \\
350 \\
398 \\
311 \\
375 \\
368 \\
415 \\
416 \\
318 \\
513 \\
460 \\
327 \\
430\end{array}$ \\
\hline $\begin{array}{l}\text { Mean } \\
\text { SD } \\
p\end{array}$ & $\begin{array}{r}33.0 \\
6.5\end{array}$ & $\begin{array}{r}36.9 \\
7.1 \\
.001\end{array}$ & $\begin{array}{r}326 \\
43\end{array}$ & $\begin{array}{r}379 \\
54 \\
0.001\end{array}$ \\
\hline
\end{tabular}

and $21 \% \mathrm{O}_{2}$ in nitrogen. By this method, duplicate determinations of $\mathrm{DL}_{\mathrm{L} \text { co }}$ on the same or different days are reproducible within $1.8 \pm 0.9 \mathrm{ml}$ per minute $\times \mathrm{mm} \mathrm{Hg}$. A correction for capillary $\mathrm{CO}$ tension in equilibrium with small amounts of carboxyhemoglobin present in the blood was made as previously described (12).
The data presented in the Tables represent the average of duplicate determinations. Paired comparison $t$ tests, with each subject serving as his own control, were used to calculate the probability values expressed in the Tables (13).

In three subjects, saphenous venous pressure was measured at the ankle during active and passive leg motion, with and without tourniquet occlusion of the leg. During both active and passive motion, the subject was seated with his feet on the pedals of a bicycle ergometer. The pedals were rotated through a circle of radius 17 $\mathrm{cm}$ at a frequency of 40 to $50 \mathrm{rpm}$. Active exercise was performed at a rate of $100 \mathrm{w}$. Pressure was measured with an indwelling polyethylene catheter, a saline-filled pressure transducer, and a photographic recorder. Reference zero was taken at the internal malleolus.

The thigh tourniquets used to occlude blood flow to or from the legs are 8-inch pneumatic cuffs that are placed as high on the thighs as possible and inflated suddenly to a pressure of $250 \mathrm{~mm} \mathrm{Hg}$ by opening a large bore connector to a previously pressurized bottle.

\section{Results}

Diffusing capacity. Passive leg motion performed sitting on a bicycle increased $\mathrm{DL}_{\mathrm{co}}$ from $33.0 \pm 6.5$ to $36.9 \pm 7.1 \mathrm{ml}$ per minute $\times \mathrm{mm} \mathrm{Hg}$, $\mathrm{p}<0.001$ (Table I). During rest, $\mathrm{DL}_{\mathrm{Co}}$ was not affected by occlusion of the circulation to the legs (Table II). Passive leg motion while the circulation was occluded produced a physiologically doubtful though statistically significant increase in $\mathrm{DL}_{\mathrm{CO}}, 35.2 \pm 7.4$ to $35.7 \pm 7.6 \mathrm{ml}$ per minute $X$ $\mathrm{mm} \mathrm{Hg}, \mathrm{p}=0.025$ (Table II). No change in $\mathrm{DL}_{\mathrm{Co}}$ was observed during passive leg motion in

TABLE II

Effects of arterial tourniquets on the responses to passive leg motion in sitting subjects

\begin{tabular}{|c|c|c|c|c|c|c|c|c|c|c|c|c|}
\hline \multirow[b]{2}{*}{ Subject } & \multicolumn{4}{|c|}{ DLCO } & \multicolumn{4}{|c|}{$\mathrm{O}_{2}$ consumption } & \multicolumn{4}{|c|}{ Minute ventilation } \\
\hline & Rest & $\begin{array}{l}\text { Passive } \\
\text { motion }\end{array}$ & Rest $+\mathrm{T}^{*}$ & $\begin{array}{l}\text { Passive } \\
\text { motion! } \\
+T^{*}\end{array}$ & Rest & $\begin{array}{l}\text { Passive } \\
\text { motion }\end{array}$ & Rest $+T^{*}$ & $\begin{array}{c}\text { Passive } \\
\text { motion } \\
+T^{*}\end{array}$ & Rest & $\begin{array}{l}\text { Passive } \\
\text { motion }\end{array}$ & Rest $+\mathrm{T}^{*}$ & $\begin{array}{c}\text { Passive } \\
\text { motion } \\
+T^{*}\end{array}$ \\
\hline & \multicolumn{4}{|c|}{$\mathrm{ml} / \mathrm{min} \times \mathrm{mm} \mathrm{Hg}$} & \multicolumn{4}{|c|}{$\mathrm{ml} / \min$} & \multicolumn{4}{|c|}{$L / \min$} \\
\hline W.D. & 37.0 & 42.6 & 38.0 & 38.9 & 264 & 410 & 360 & 480 & 8.00 & 13.90 & 9.60 & 13.40 \\
\hline T.S. & 31.6 & 37.3 & 34.4 & 35.9 & 294 & 327 & 327 & 392 & 8.10 & 8.57 & 7.87 & 10.59 \\
\hline J.C. & 33.0 & 39.9 & 34.8 & 35.3 & 295 & 415 & 323 & 412 & 8.04 & 10.35 & 8.20 & 9.75 \\
\hline B.M. & 20.9 & 22.4 & 20.7 & 20.7 & 293 & 416 & 309 & 385 & 10.70 & 31.10 & 12.30 & 26.00 \\
\hline J.R. & $\mathbf{3 0 . 3}$ & 34.2 & 30.6 & 30.8 & 256 & 318 & 281 & 347 & 6.15 & 7.92 & 6.24 & 8.25 \\
\hline B.H. & 39.9 & 48.0 & 46.6 & 47.2 & 328 & 513 & 353 & 486 & 8.66 & 23.65 & 7.30 & 13.20 \\
\hline B.L. & 43.4 & 47.8 & 41.9 & 42.7 & 350 & 460 & 372 & 520 & 7.55 & 7.68 & 7.52 & 10.20 \\
\hline M.L. & 40.3 & 44.7 & 37.9 & 38.4 & 351 & 377 & 287 & 510 & 9.02 & 10.75 & 8.46 & 12.60 \\
\hline J.O. & 30.8 & 35.2 & 31.9 & 31.5 & 292 & 430 & 318 & 522 & 9.07 & 11.37 & 10.85 & 15.42 \\
\hline Mean & 34.1 & 39.1 & 35.2 & 35.7 & 303 & 407 & 326 & 450 & 8.37 & 13.92 & 8.70 & 13.27 \\
\hline SD & 6.8 & 8.1 & 7.4 & 7.6 & 34 & 61 & 32 & 67 & 1.24 & 8.08 & 1.90 & 5.26 \\
\hline p & $\leftarrow$ & 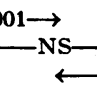 & & $\stackrel{.0}{\longleftarrow} 0.025 \longrightarrow$ & \multicolumn{2}{|c|}{$\stackrel{\leftarrow 0.001 \longrightarrow}{\longrightarrow}$} & $\underset{-0.05}{\longleftrightarrow}$ & $\begin{array}{r}01 \longrightarrow \\
\longrightarrow\end{array}$ & $\longleftarrow$ & $\longrightarrow \mathrm{NS}-$ & $\stackrel{\longleftrightarrow}{\longrightarrow} 0.0$ & $\begin{array}{r}\longrightarrow \\
\longrightarrow\end{array}$ \\
\hline
\end{tabular}

* Thigh tourniquets inflated to $250 \mathrm{~mm} \mathrm{Hg}$. 
TABLE III

Pulmonary diffusing capacity and oxygen consumption during passive leg motion in supine normal subjects

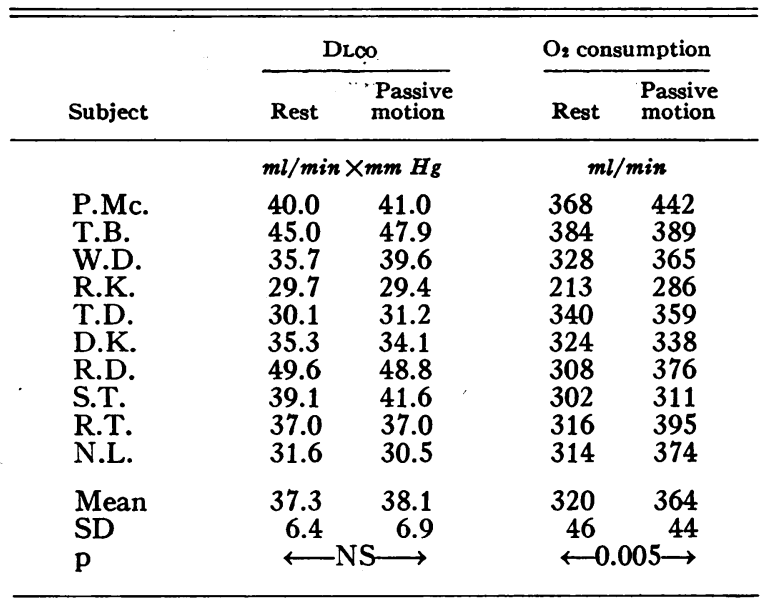

supine subjects (Table III). As has been observed by others $(11,14,15)$, DL ${ }_{c o}$ was higher in supine than upright subjects (Tables $I$ and III). The change in $\mathrm{DL}_{\mathrm{co}}$ that occurs in the upright position during passive leg motion occurs
TABLE IV

Early appearance of the change in DLco during passive leg motion in sitting subjects

\begin{tabular}{|c|c|c|c|}
\hline \multirow[b]{2}{*}{ Subject } & \multicolumn{3}{|c|}{ DLCo } \\
\hline & Rest & 10 seconds* & 2 minutes* \\
\hline & \multicolumn{3}{|c|}{$m l / \min \times m m \mathrm{Hg}$} \\
\hline $\begin{array}{l}\text { P.Mc. } \\
\text { C.H. } \\
\text { R.T. } \\
\text { D.K. } \\
\text { S.G. } \\
\text { R.D. } \\
\text { N.L. } \\
\text { M.L. }\end{array}$ & $\begin{array}{l}36.2 \\
23.5 \\
36.5 \\
38.5 \\
26.1 \\
42.4 \\
28.6 \\
33.3\end{array}$ & $\begin{array}{l}40.0 \\
29.9 \\
37.7 \\
43.9 \\
31.0 \\
48.8 \\
32.0 \\
36.7\end{array}$ & $\begin{array}{l}40.0 \\
28.3 \\
36.8 \\
43.9 \\
34.3 \\
47.5 \\
30.8 \\
36.5\end{array}$ \\
\hline $\begin{array}{l}\text { Mean } \\
\text { SD } \\
\mathrm{p}\end{array}$ & $\begin{array}{c}33.1 \\
6.0 \\
\leftarrow\end{array}$ & 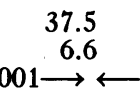 & $\begin{array}{r}37.3 \\
6.4 \\
\mathrm{NS}\end{array}$ \\
\hline
\end{tabular}

* After the beginning of passive leg motion.

within the first 10 seconds of activity, after which no further increase occurs (Table IV).

Oxygen consumption. Passive leg motion, whether supine, upright, or with occluding tourniquets on the legs, increases $\mathrm{O}_{2}$ consumption slightly (Tables I, II, and III). The average in-

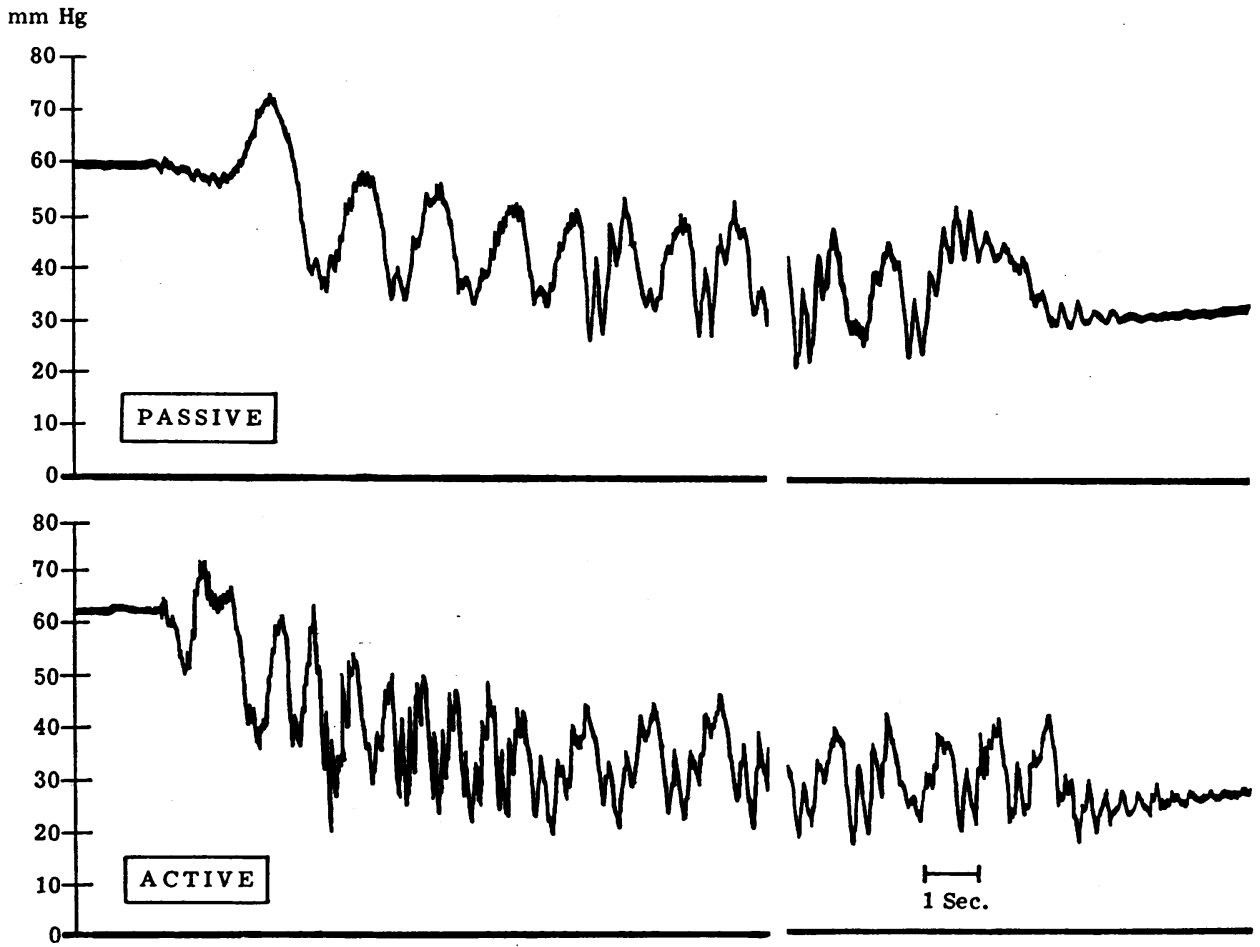

Fig. 1. Saphenous venous pressure measured in subject W.D. during passive leg MOTION ( $\mathrm{O}_{2}$ CONSUMPTION, 383 ML PER MINUTE) AND ACTIVE BICYCLE EXERCISE $\left(\mathrm{O}_{2}\right.$ CONSUMPTION, 1,179 ML PER MINUTE). 
TABLE V

Saphenous venous pressure at the ankle following active and passive leg motion

\begin{tabular}{|c|c|c|c|c|c|c|}
\hline \multirow[b]{2}{*}{ Subject } & \multirow[b]{2}{*}{ Rest } & \multirow[b]{2}{*}{$\begin{array}{c}\text { Active } \\
\text { exercise }\end{array}$} & \multirow[b]{2}{*}{$\begin{array}{l}\text { Passive } \\
\text { motion }\end{array}$} & \multicolumn{3}{|c|}{ Tourniquets inflated to $250 \mathrm{~mm} \mathrm{Hg}$} \\
\hline & & & & Rest & $\begin{array}{c}\text { Active } \\
\text { exercise }\end{array}$ & $\begin{array}{l}\text { Passive } \\
\text { motion }\end{array}$ \\
\hline & $m m \mathrm{Hg}$ & $m m \mathrm{Hg}$ & $m m \mathrm{Hg}$ & $m m H g$ & $m m \mathrm{Hg}$ & $m m \mathrm{Hg}$ \\
\hline W.D. & $80^{*}$ & 39 & $48^{\circ}$ & 102 & 102 & 98 \\
\hline B.H. & 55 & 11 & 33 & 81 & 81 & 81 \\
\hline B.M. & 60 & 26 & 32 & 62 & 61 & 72 \\
\hline
\end{tabular}

* Pressure measurements are taken at the end of this period of motion with the leg in the same position and are referred to a zero level at the internal malleolus.

crease in $\mathrm{O}_{2}$ consumption during passive motion was $53 \pm 50 \mathrm{ml}$ per minute in the upright position and $44 \pm 30 \mathrm{ml}$ per minute in the supine position. In the group in whom occluding tourniquets were used, $\mathrm{O}_{2}$ consumption increased 104 $\pm 53 \mathrm{ml}$ per minute during passive motion before tourniquet application and $124 \pm 46 \mathrm{ml}$ per minute during passive motion after tourniquet inflation (Table II). The presence of the bulk of the tourniquets on the thighs in the latter group caused a certain degree of clumsiness during passive motion. This is reflected in the greater increase in $\mathrm{O}_{2}$ consumption during passive motion in this group.

Ventilation. Passive motion of the extremities increased minute ventilation from $8.37 \pm 1.24$ to $13.92 \pm 8.08 \mathrm{~L}$ per minute $(\mathrm{p}=0.05)$ before tourniquet inflation and from $8.70 \pm 1.90$ to 13.27 $\pm 5.26 \mathrm{~L}$ per minute $(p=0.01)$ after tourniquet inflation. Tourniquet inflation did not affect the magnitude of the increase.

Saphenous venous pressure. In the three subjects in whom it was measured, pressure in a superficial leg vein was decreased abruptly with the onset of motion of the leg, whether active or passive (Table V and Figure 1). Whether leg motion was active or passive, saphenous venous pressure decreased within the first 2 seconds of the beginning of motion. This decrease in pressure was completely blocked by inflation of thigh tourniquets.

\section{Discussion}

It is well established that leg exercise in normal men pumps blood out of the superficial veins of the legs and decreases the pressure recorded from these veins for periods up to a minute following the exercise (16-19). This phenomenon is dependent upon the integrity of the system of valves in the veins of the extremity (17-18). Using a plethysmographic technique, Grill observed a decreased volume of exercising extremities early during the period of exercise (20). In the present study saphenous vein pressure decreased during passive pumping motion of the lower extremities. This change did not occur when egress of blood from the leg was prevented by tourniquet occlusion.

The presence of a normal venous pumping mechanism is required for a normal cardiovascular response to postural change (21-22) and to exercise (23-24). It seems established that the venous pumping of exercise does participate in the return of blood to the central circulation in upright exercise. We believe that the passive motion used in this study has a similar effect.

The normal dependent legs probably contain 300 to $800 \mathrm{ml}$ more blood than the legs in a supine position (25-26). Sjöstrand has suggested that a large portion of this volume difference is transferred to the lungs when normal men change from an upright to a supine position (26). Wang, Blomquist, Rowell, and Taylor measured central blood volume by means of an indicator dilution technique with central aortic sampling and found that central blood volume decreased about $20 \%$ when normal men changed from supine to upright postures and that exercise in an upright position returned the central blood volume to its supine value (27). On the basis of these observations, it seems established that exercise in an upright position, or the change from upright to supine posture, increases the central pool available for pulmonary capillary filling.

The resting transmural pressures normally available in the low pressure pulmonary system may well be inadequate for filling and perfusing 
the capillaries of the upper zones of the upright lung (28). Observations based on the use of radioactive gases have in fact shown relative underperfusion of the lung in normal men in an upright position (28-29). This upper zone underperfusion is not present during exercise or in a resting supine position $(28,30)$. There is a similar gradient of carbon monoxide absorption (31), and since carbon monoxide absorption is virtually independent of capillary blood flow, this suggests a gradient of pulmonary capillary blood volume. This does not imply that capillary filling and perfusion are totally independent phenomena, merely that once a capillary is filled as perfusion begins, $\mathrm{CO}$ uptake from that capillary is virtually independent of the rate of perfusion (7).

In upright normal subjects, whose upper zone pulmonary capillaries are said to be poorly perfused, the present observations show that passive pumping motion of the legs increases $\mathrm{DL}_{\mathrm{CO}}$, but such motion produces no change in supine subjects whose upper pulmonary capillaries are already well filled. Furthermore, $\mathrm{DL}_{\mathrm{CO}}$ is not increased during passive leg motion in an upright position if egress of blood from the legs is blocked by thigh cuffs.

The absolute magnitude of the increase in $\mathrm{DL}_{\text {co }}$ produced by passive motion is not greatly different from that produced by G-suit inflation $(5,9)$, which increases central vascular pressures to levels much higher than would be expected with simple passive motion of the extremities. The evidence available suggests that the size of the effective pulmonary capillary bed is affected by shifts of blood to or from the thorax, but the limits of this passive effect have not been defined.

Passive motion of the extremities might be expected to produce the effect observed by one of several mechanisms: 1) reflex effect on the systemic vascular reservoir; 2) local reflex effect on the pulmonary vascular bed; 3) moving blood lying stagnant in the dependent legs and containing some humoral substance to the lung, where it either enlarges the pulmonary vascular bed or alters the rate of reaction of carbon monoxide with hemoglobin; or 4) actively pumping blood from the legs to the central circulation by the venous pump.
Merritt and Weissler were unable to demonstrate any increase in venomotor tone in an isolated vein segment during passive exercise (32). The present observation that the effect of passive motion can be blocked by occluding tourniquets further suggests that the effect on D Lo $_{\text {co }}$ is not reflex in origin. The maintenance of the increase in $\mathrm{DL}_{\mathrm{Co}}$ over a 3-minute period of passive motion suggests that it is not dependent upon the mobilization of some humoral agent liberated from "stagnant" blood pumped into the circulation from the legs, though the possibility cannot be excluded. Ross, Frayser, and Hickam were unable to find evidence for such a humoral agent released from ischemic legs even after 10 minutes of tourniquet ischemia (1).

DL $L_{\text {Co }}$ increases during the first 10 seconds of muscular exercise (33). This study shows that this early change also occurs during passive motion of the legs and that the effect of passive motion on $\mathrm{DL}_{\mathrm{Co}}$ can be prevented by blocking egress of blood from the legs. It seems most plausible that this early rise in $\mathrm{DL}_{\mathrm{co}}$ during exercise or passive motion is related to the observations reported by Guyton, Douglas, Langston, and Richardson (34). They showed that cardiac output and mean circulatory pressure increased instantly with the onset of muscular exercise in dogs and, by the use of appropriate blocking agents, showed that this phenomenon is the result of increased venous return to the central circulation and decreased peripheral vascular capacity associated with skeletal muscle contraction rather than sympathetic reflex activity. Our results suggest that the early response of $\mathrm{DL}_{\mathrm{Co}}$ to exercise may be associated with transfer of blood from the pumping legs rather than reflex activity, since the effect observed with passive pumping can be blocked by tourniquet inflation.

The pressure-flow relationships obtaining in the pulmonary capillary bed during this activity are undefined. The results of previous studies, however, suggest that the observed increase in $\mathrm{DL}_{\mathrm{CO}}$ is not dependent upon any increase in pulmonary capillary flow that may have occurred $(1,5,6)$. Pulmonary vascular transmural pressure may have increased during passive motion of the legs, and such an increase could explain the observed changes in $\mathrm{DL}_{\mathrm{CO}}$; however, since 
the $\mathrm{DL}_{\mathrm{CO}}$ change was blocked by cuffing the thighs, it seems that such a change probably requires the blood pumped from the legs during passive motion and was probably dependent upon a change in pulmonary blood volume rather than altered intrathoracic pressure or pulmonary vascular compliance.

The physiologic determinants of changes in breath-holding $\mathrm{DL}_{\mathrm{Co}}$ are complex, and the limitations of the method have been described at length (3). If we assume no change in the diffusivity of the pulmonary capillary membrane per unit area, the abrupt changes in $\mathrm{DL}_{\mathrm{Co}}$ produced in this study must depend on changes in the area available for diffusion, the instantaneous mass of hemoglobin available for carbon monoxide absorption, or the rate of reaction of carbon monoxide with hemoglobin. If $\theta$, the reaction constant, and the pulmonary capillary hematocrit are not altered under the conditions of this study, changes in $\mathrm{DL}_{\mathrm{CO}}$ must reflect changes in the instantaneous volume of blood available for gas exchange, since the capillary volume and surface area are geometrically related.

We believe that the abrupt change in $\mathrm{DL}_{\mathrm{CO}}$ occurring during the first 10 seconds of passive leg motion and blocked by occlusive thigh cuffs can best be explained on the basis of an abrupt increase in pulmonary blood volume produced by the action of the venous pump. This does not imply that the blood in the legs at the onset of motion is transported to the lungs instantly against the hydrostatic gradient but that, with the onset of the action of the venous pump, peripheral vascular capacity is abruptly decreased and blood is transferred from the systemic to the pulmonary reservoir.

These observations suggest that the maintenance of pulmonary capillary blood volume, like the maintenance of cardiac filling, is dependent upon the degree of filling of the central vascular reservoir, and that in upright postures, the venous pumping action of the legs contributes to this filling.

The small increases in $\mathrm{O}_{2}$ consumption observed in this study are similar to those previously found in experiments using conscious men (35). Since this increase could not be altered by preventing return of blood from the legs, it is probable that the increase in oxygen consump- tion observed is dependent upon increased muscular activity in areas other than those being passively moved. Since the tourniquet inflation did, however, block the increase in $\mathrm{DL}_{\mathrm{CO}}$, the increased oxygen consumption and increased $\mathrm{DL}_{\mathrm{co}}$ of passive motion are probably not related.

Passive motion of the extremities, even with tourniquets stopping flow to or from the affected areas, increases minute volume of ventilation; this has been observed previously (36).

\section{Summary}

Passive motion of the lower extremities in upright normal men decreases the pressure in the saphenous vein at the ankle and increases breathholding diffusing capacity $\left(\mathrm{DL}_{\mathrm{CO}}\right)$. This effect is present in the first 10 seconds of passive leg motion. DLco does not increase during passive motion of the legs in sitting subjects if the egress of blood from the legs is prevented by the inflation of thigh tourniquets to $250 \mathrm{~mm} \mathrm{Hg}$ or in supine subjects. This study suggests that a portion of the increase in $\mathrm{DL}_{\mathrm{co}}$ that occurs with exercise in an upright position is dependent upon pumping of blood from the exercising part to the lung and is independent of any generalized reflex action. It suggests further that the venous pumping mechanism is one of the determinants of pulmonary capillary filling in upright postures.

\section{References}

1. Ross, J. C., R. Frayser, and J. B. Hickam. A study of the mechanism by which exercise increases the pulmonary diffusing capacity for carbon monoxide. J. clin. Invest. 1959, 38, 916.

2. Roughton, F. J. W. The average time spent by blood in the human lung capillary and its relation to the rates of $\mathrm{CO}$ uptake and elimination in man. Amer. J. Physiol. 1945, 143, 621.

3. Forster, R. E. Exchange of gases between alveolar air and pulmonary capillary: blood: pulmonary diffusing capacity. Physiol. Rev. 1957, 37, 391.

4. Johnson, R. L., Jr., W. S. Spicer, J. M. Bishop, and R. E. Forster. Pulmonary capillary blood volume, flow, and diffusing capacity during exercise. J. appl. Physiol. 1960, 15, 893.

5. Daly, W. J., J. C. Ross, and R. H. Behnke. The effect of changes in the pulmonary vascular bed produced by atropine, pulmonary engorgement, and positive-pressure breathing on diffusing and mechanical properties of the lung. J. clin. Invest. 1963, 42, 1083. 
6. Turino, G. M., M. Brandfonbrener, and A. P. Fishman. The effect of changes in ventilation and pulmonary blood flow on the diffusing capacity of the lung. J. clin. Invest. 1959, 38, 1186.

7. Hatch, T. F. Carbon monoxide uptake in relation to pulmonary performance. Arch. industr. Hyg. 1952, 6, 1.

8. Ross, J. C., R. W. Reinhart, J. F. Boxell, and L. H. King, Jr. Relationship of increased breath-holding diffusing capacity to ventilation in exercise. $\mathrm{J}$. appl. Physiol. 1963, 18, 794.

9. Ross, J. C., T. H. Lord, and G. D. Ley. Effect of pressure-suit inflation on pulmonary diffusing capacity. J. appl. Physiol. 1960, 15, 843.

10. Ogilvie, C. M., R. E. Forster, W. S. Blakemore, and J. W. Morton. A standardized breath holding technique for the clinical measurement of the diffusing capacity of the lung for carbon monoxide. J. clin. Invest. 1957, 36, 1.

11. Daly, W. J., S. T. Giammona, J. C. Ross, and H. Feigenbaum. Effects of pulmonary vascular congestion on postural changes in the perfusion and filling of the pulmonary vascular bed. J. clin. Invest. 1964, 43, 68.

12. Forster, R. E., W. S. Fowler, D. V. Bates, and B. Van Lingen. The absorption of carbon monoxide by the lungs during breathholding. $\mathrm{J}$. clin. Invest. 1954, 33, 1135.

13. Snedecor, G. W., and W. G. Cochran. Statistical Methods Applied to Experiments in Agriculture and Biology, 5th ed. Ames, Iowa State College Press, 1956.

14. Bates, D. V., and J. F. Pearce. The pulmonary diffusing capacity; a comparison of methods of measurement and a study of the effect of body position. J. Physiol. (Lond.) 1956, 132, 232.

15. Lewis, B. M., W. T. McElroy, E. J. Hayford-Welsing, and L. C. Samberg. The effects of body position, ganglionic blockade, and norepinephrine on the pulmonary capillary bed. J. clin. Invest. 1960, 39, 1345.

16. Pollack, A. A., and E. H. Wood. Venous pressure in the saphenous vein at the ankle in man during exercise and changes in posture. J. appl. Physiol. 1949, 1, 649.

17. Hickam, J. B., R. P. McCulloch, and R. J. Reeves. Normal and impaired function of the leg veins. Amer. Heart J. 1949, 37, 1017.

18. Walker, A. J., and C. J. Longland. Venous pressure measurement in the foot in exercise as an aid to investigation of venous disease in the leg. Clin. Sci. 1950, 9, 101.

19. Höjensgard, I. C., and H. Stürup. Static and dynamic pressures in superficial and deep veins of the lower extremity in man. Acta physiol. scand. 1952, 27, 49.

20. Grill, C. Plethysmographische Untersuchungen über des Arm-und Beinvolumen während und nach der Arbeit, welche die Zirkulationsverhaltnisse im
Gefässystem der Extremitäten beleuchten. Skand. Arch. Physiol. 1933, 67, 1.

21. Chapman, E. M., and E. Asmussen. On the occurrence of dyspnea, dizziness and precordial distress occasioned by the pooling of blood in varicose veins. J. clin. Invest. 1942, 21, 393.

22. Arenander, E. Hemodynamic effects of varicose veins and results of radical surgery. Acta chir. scand. 1960, suppl. 260.

23. Arenander, E., and A. Carlsten. Physical work capacity in patients with varicose veins. Acta chir. scand. 1961, 122, 520.

24. Grimby, G., N. J. Nilsson, and H. Sanne. Cardiac output during exercise in patients with varicose veins. Scand. J. clin. Lab. Invest. 1964, 16, 21.

25. Asmussen, E. The distribution of the blood between the lower extremities and the rest of the body. Acta physiol. scand. 1943, 5, 31.

26. Sjöstrand, T. The regulation of the blood distribution in man. Acta physiol. scand. 1952, 26, 312.

27. Wang, Y., G. Blomquist, L. B. Rowell, and H. L. Taylor. Central blood volume during upright exercise in normal subjects. Fed. Proc. 1962, 21, 124.

28. West, J. B., and C. T. Dollery. Distribution of blood flow and ventilation-perfusion ratio in the lung, measured with radioactive $\mathrm{CO}_{2}$. J. appl. Physiol. 1960, 15, 405.

29. Ball, W. C., Jr., P. B. Stewart, L. G. S. Newsham, and D. V. Bates. Regional pulmonary function studied with xenon $^{133}$. J. clin. Invest. 1962, 41, 519.

30. Bryan, A. C., L. G. Bentivoglio, F. Beerel, H. MacLeish, A. Zidulka, and D. V. Bates. Factors affecting regional distribution of ventilation and perfusion in the lung. J. appl. Physiol. 1964, 19, 395.

31. Dollery, C. T., N. A. Dyson, and J. D. Sinclair. Regional variations in uptake of radioactive $\mathrm{CO}$ in the normal lung. J. appl. Physiol. 1960, 15, 411.

32. Merritt, F. L., Jr., and A. M. Weissler. Reflex venomotor alterations during exercise and hyperventilation. Clin. Res. 1959, 7, 238.

33. Krumholz, R. A., and J. C. Ross. Effect of atropine and reserpine on pulmonary diffusing capacity during exercise in man. J. appl. Physiol. 1964, 19, 465.

34. Guyton, A. C., B. H. Douglas, J. B. Langston, and T. Q. Richardson. Instantaneous increase in mean circulatory pressure and cardiac output at onset of muscular activity. Circulat. Res. 1962, 11, 431.

35. Otis, A. B. Application of Gray's theory of respiratory control to the hyperpnea produced by passive movement of the limbs. J. appl. Physiol. 1949, 1, 717.

36. Harrison, T. R., W. G. Harrison, J. A. Calhoun, and J. P. Marsh. Congestive heart failure. XVII. The mechanism of dyspnea on exertion. Arch. intern. Med. 1932, 50, 690. 